\title{
Characterization of Chinese eggplant isolates of the fungal pathogen Verticillium dahliae from different geographic origins
}

\author{
Z. Xu' ${ }^{1,2}$, Z. Ali ${ }^{2,3}$, X. Hou ${ }^{1}$, H. Li ${ }^{1}$, J.X. Yi ${ }^{1,2}$ and P.A. Abbasi ${ }^{4}$ \\ ${ }^{1}$ Nanjing Agriculture University, Nanjing, China \\ ${ }^{2}$ Institute of Agri-Biotechnology, Jiangsu Academy of Agricultural Sciences, \\ Nanjing, China \\ ${ }^{3}$ Visiting Scientist, Department of Plant Breeding and Genetics, \\ University of Agriculture, Faisalabad, Pakistan \\ ${ }^{4}$ Agriculture and Agri-Food Canada, \\ Southern Crop Protection and Food Research Centre, London, ON, Canada \\ Corresponding author: P.A. Abbasi / J.X. Yi \\ E-mail: Pervaiz.Abbasi@agr.gc.ca/yij@jaas.ac.cn
}

Genet. Mol. Res. 12 (1): 183-195 (2013)

Received May 26, 2012

Accepted December 3, 2012

Published January 24, 2013

DOI http://dx.doi.org/10.4238/2013.January.24.11

\begin{abstract}
Verticillium dahliae is a fungal pathogen that causes wilt disease in a wide range of host plants. Characterization of virulence, morphological, and molecular variations among $V$. dahliae isolates from different geographic origins is essential for any breeding program aimed at producing plant cultivars resistant to this disease. We characterized virulence variation among $V$. dahliae isolates from Chinese cultivated eggplant grown in Northeast China by pathogenicity testing on susceptible, moderately resistant, and resistant eggplant accessions in a glasshouse using a root-dipping method of infection. These isolates were also characterized for morphological features based on growth on potato dextrose agar media and for genetic variation based on ISSR markers. All 12 isolates were divided into three pathotypes based on the virulence, i.e., strong, moderate, or weak type. Three isolates were
\end{abstract}


categorized as defoliating pathotypes, with strong virulence, and the rest of the isolates were categorized as non-defoliating pathotypes, with moderate to weak virulence. The eggplant isolates were classified into three morphological types or morphotypes, hypha, hypha-sclerotia, and sclerotia; no significant correlations were detected between pathotypes and morphotypes or geographic origins. ISSR fingerprinting indicated genetic diversity among isolates, ranging from 0.26 to 0.69 . Specific fingerprint types were not correlated with either pathotype or morphotype. However, ISSR analyses did reveal two clusters in which the isolates in each share the same or neighboring geographic origins.

Key words: ISSR-PCR; Morphotype; Pathogenicity; Pathotype; Wilt disease

\section{INTRODUCTION}

Verticillium dahliae Klebahn is a soilborne fungal pathogen that causes wilt disease in a wide range of host plants including many economically important solanaceous crops such as tomato, potato, and eggplant (Klosterman et al., 2009). The disease symptoms are the yellowing and necrosis of leaves in a characteristic V-shaped pattern followed by wilting, stunting, and death (Fradin and Thomma, 2006). The brown discoloration of the vascular tissue of the wilted plants is visible when the stems are cut longitudinally. Microsclerotia are the main survival structures of $V$. dahliae, and they may persist for up to 14 years under field conditions in the absence of a host (Wilhelm, 1955). The microsclerotia germinate in the vicinity of host roots and infect roots through wounds caused by cultivation, secondary root formation, or plant-parasitic nematode feeding. The disease is favored by cool air and soil temperatures and can be a major constraint in the production of these vegetable crops worldwide (Fradin and Thomma, 2006; Klosterman et al., 2009).

Morphological features or vegetative compatibility group (VCG) tests are conventionally used to distinguish Verticillium spp (Puhalla and Hummel, 1983; Joaquim and Rowe, 1990, 1991). However, these methods may be unsuitable for making distinctions between the isolates of a particular Verticillium species in terms of virulence (Usami et al., 2002). Pathogenicity tests using various cultivars of a host can separate these indistinguishable isolates into various virulence types based on host reactions. V. dahliae isolates have been categorized into eggplant, tomato, and sweet pepper pathotypes based on their pathogenicity to host plants (Hagiwara, 1990; Komatsu et al., 2001).

Polymerase chain reaction (PCR) and DNA-based molecular techniques are now routinely used for the diagnosis and identification of individuals or clones within fungal populations in ecological and epidemiological studies. These techniques have been used for the characterization and differentiation of Verticillium spp (Carder and Barbara, 1991, 1994; Okoli, et al., 1993, 1994; Arora et al., 1996; Koike et al., 1996; Dobinson et al., 1998; Komatsu et al., 2001). However, the isolates included in these studies were collected from different species or varieties of host plants, not from a specific plant. The inter-simple sequence repeat (ISSR) approach is similar to the random amplified polymorphic DNA (RAPD) technique except that ISSR primer sequences are longer and designed from microsatellite regions that are abundant throughout the plant and fungal genome (Zietkiewicz et al., 1994; Wang et al., 2005). 
These markers generally reveal higher levels of polymorphism owing to higher annealing temperatures and longer primer sequences. They are easy to use and are highly reproducible compared with other techniques such as RAPD, and no prior sequence knowledge is required. ISSR-PCR has been successfully used to describe population structures of mycorrhizal fungi (Grünig et al., 2001; Rodrigues et al., 2004).

Verticillium wilt is an important disease in eggplants in Northeast China. It occurred infrequently in only part of the area in 1950s; however, V. dahliae has been found in all eggplantgrowing areas in northern China in recent years (Yi, 1998). The spread of this pathogen is the main concern, but the lack of characterization of genetic variation of pathogenicity among eggplant isolates from various geographic locations is an additional concern. This characterization is essential to the development of disease management strategies, including breeding programs in each location of China aiming to produce plant cultivars resistant to the disease.

The objectives of this study were: to identify the virulence variation among $V$. dahliae isolates from Chinese cultivated eggplant based on reaction in susceptible, moderately resistant, or resistant eggplant accessions; to examine genetic variations among the isolates with ISSR fingerprinting, and to determine whether a relationship among pathogenicity, morphological characters, and molecular patterns exists.

\section{MATERIAL AND METHODS}

\section{Fungal cultures and isolate identification}

Eggplants infected with $V$. dahliae and showing Verticillium wilt symptoms were collected in 2003 from cropping areas located in regions representing more than $70 \%$ of the eggplant production areas in China. A total of 12 isolates were recovered from the infected plant samples from six provinces (Table 1). For isolations, small sections $(0.5$ to $1 \mathrm{~cm})$ of eggplant stems showing wilt symptoms were cut with a sterilized razor and their surfaces were disinfested by dipping in $0.5 \%$ sodium hypochlorite for $3 \mathrm{~min}$ followed by 3 rinses in sterile distilled water (SDW). The washed pieces were dried on sterile filter paper and placed aseptically on potato dextrose agar (PDA) medium amended with $50 \mathrm{mg} / \mathrm{L}$ oxytetracycline on $9-\mathrm{cm}$ Petri plates. The plates were incubated at room temperature $\left(22^{\circ}-24^{\circ} \mathrm{C}\right)$ in the dark for 2 weeks, and the actively growing fungal colonies were transferred onto new PDA plates for further purification and sporulation development.

Table 1. Isolates of Verticillium dahliae obtained from cultivated eggplant from six provinces of China during 2003.

\begin{tabular}{ll}
\hline Isolate & Geographic origin \\
\hline Vd196 & Jiangsu \\
Vd197 & Jiangsu \\
Vd198 & Jiangsu \\
Vd199 & Jiangsu \\
Vd200 & Tianjin \\
Vd201 & Liaoning \\
Vd202 & Shandong \\
Vd203 & Shandong \\
Vd204 & Shandong \\
Vd206 & Hebei \\
Vd207 & Neimeng \\
Vd210 & Neimeng \\
\hline
\end{tabular}


For morphological studies, all isolates were cultured on PDA plates and colony characteristics such as color, shape and structure were recorded. Conidia were harvested by flooding the PDA plates with SDW and agitating the plates to release spores. The length and width of 20 conidia in the suspension were then measured using a microscope and a hemocytometer. The actual measurements of conidia were converted from the hemocytometer scale into micrometers.

\section{Pathogenicity tests}

The 12 isolates of $V$. dahliae were characterized for virulence variation by testing for pathogenicity on susceptible, moderately resistant, and resistant eggplant accessions in a glasshouse using a root-dipping method described by Xiao and Lin (1995). Two identical pathogenicity trials were conducted from April to June and August to November in 2004. The accession numbers of 3 eggplant cultivars used in these trials were CGN18564, a resistance eggplant introduced from Wageningen University, Netherlands; Sm97161 cv. Changting Local, an eggplant landrace with moderate resistance (Xiao and Lin, 1995), and Sm90017 cv. Qiye Qie, a susceptible eggplant cultivar (Yi et al., 2000). The eggplant seeds were surface sterilized in $1.5 \%$ sodium hypochlorite for $4 \mathrm{~min}$ and then washed several times in tap water before sowing. Seedlings were grown in pots containing disinfested soil and compost (1:1, $\mathrm{v} / \mathrm{v}$ ) mixture under greenhouse conditions until the three-leaf stage of development. Fungal inoculum was grown for 7 days in potato dextrose broth as a shake culture. Roots of the eight seedlings from each of the 3 eggplant accessions at the three-leaf stage were immersed to the cotyledons for $2 \mathrm{~min}$ in a conidial suspension $\left(10^{6}\right.$ conidia/mL SDW) of each of the 12 isolates. The seedlings were carefully replanted and watered on alternate days until 45 days after inoculation. Negative controls consisted of seedlings immersed in water.

The severity of wilt symptoms on the foliage of individual eggplant was scored 35 days after inoculation by using a 1-7 rating scale: $1=$ healthy without any symptom of necrosis; $2=1-20 \%$ of leaves showing necrosis; $3=21-40 \%$ of leaves showing necrosis; $4=$ $41-60 \%$ of leaves showing necrosis; $5=61-80 \%$ of leaves showing necrosis; $6=81-100 \%$ of leaves showing necrosis; 7 = plant death. Eggplant accessions were assessed based on their reaction to $12 \mathrm{~V}$. dahliae isolates by calculating mean disease severity index (DSI) values using the following formula:

$$
\mathrm{D} \mathrm{SI}=\frac{\sum\left(i \times P_{i}\right)}{i_{\max } \times P_{\text {totat }}} \times 100
$$

where $i$ represents the disease severity rating $(i=1,2, \ldots 7), P i$ represents the number of plants with the rating $i, i_{\max }$ is the highest disease rating, i.e., 7 , and $P_{\text {total }}$ is the total number of inoculated plants in each accession. The reaction of the 3 eggplant accessions to $V$. dahliae was designated as resistance (R), moderate resistance (MR), or susceptible (S) based on DSI values. An accession was designated as R if the DSI was no higher than 25, MR if the DSI was 25.1 to 45.0 , and $\mathrm{S}$ if the DSI was 45.1 and higher. The isolates of $V$. dahliae were grouped into 3 pathotypes depending on their reactions in three eggplant accessions CGN14726, Sm97161, and Sm90017: weakly virulent with R-R-S/MR reactions on 3 eggplant accessions, moderately virulent with R-MR-S reaction on three eggplant accessions, and strongly virulent with R-S-S reactions on 3 eggplant accessions, respectively. 


\section{DNA extraction and ISSR-PCR amplification}

Total genomic DNA was extracted from fungal mycelia grown in potato dextrose broth as shake cultures following a protocol described by Lee and Taylor (1990) with some modifications. Twenty-eight of a complete set of 77 primers that yielded repeatable bands in preliminary screening were selected (Table 2). The PCR $(20 \mu \mathrm{L})$ consisted of $0.25 \mu \mathrm{M}$ primer, $250 \mu \mathrm{M}$ deoxyribonucleotide triphosphate, $2 \mu \mathrm{L}$ 10X reaction buffer, 1.0 U Taq DNA polymerase (Takara Co. Ltd., Japan), $2.5 \mathrm{mM} \mathrm{MgCl}_{2}$, and fungal DNA. The cycling profile consisted of $5 \mathrm{~min}$ at $94^{\circ} \mathrm{C}$ followed by 40 cycles of $30 \mathrm{~s}$ at $94^{\circ} \mathrm{C}, 45 \mathrm{~s}$ at $48^{\circ} \mathrm{C}$, and 2 min at $72^{\circ} \mathrm{C}$; a final extension of $6 \mathrm{~min}$ was carried out at $72^{\circ} \mathrm{C}$. Amplification reactions were carried out in a PTC- $100^{\mathrm{TM}}$ thermocycler (MJ Research Co., Ltd., Waltham, MA, USA). The amplification products were separated via electrophoresis on 2\% agarose gels in TAE buffer (40 $\mathrm{mM}$ Tris-acetate, $\mathrm{pH} 8.0$, and $1 \mathrm{mM}$ ethylenediaminetetraacetic acid) stained with ethidium bromide and visualized under ultraviolet light. The length of the amplification products was estimated through comparison with a DL2000 DNA ladder (Takara Co. Ltd.). All reactions were repeated 3 times on different DNA preparations.

\begin{tabular}{llcc}
\multicolumn{2}{c}{ Table 2. Polymorphic bands generated in inter-simple sequence repeat (ISSR) analyses. } \\
\hline Primer & Sequence (5'-3') & Polymorphic fragments & Range of PCR product (bp) \\
\hline ISSR04 & [ACACACACACACACAC]AG & 17 & $375-3398$ \\
ISSR05 & [ACACACACACACACAC]TG & 9 & $547-3363$ \\
ISSR08 & [ATGATGATGATGATGATG] & 18 & $453-1897$ \\
ISSR09 & [CTCCTCCTCCTCCTCCTC] & 13 & $376-1713$ \\
ISSR10 & [GAAGAAGAAGAAGAAGA] & 14 & $283-2596$ \\
ISSR24 & [ACACACACACACACAC]TC & 18 & $282-3304$ \\
ISSR25 & [ACACACACACACACAC]CA & 21 & $336-3381$ \\
ISSR26 & [ACACACACACACACAC]CC & 8 & $655-2991$ \\
ISSR28 & [TGTGTGTGTGTGTGTG]CC & 7 & $351-1525$ \\
ISSR31 & [TGTGTGTGTGTGTGTGT] & 6 & $342-1227$ \\
ISSR32 & [AGAGAGAGAGAGAGAG]AC & 13 & $341-3120$ \\
ISSR34 & [AGAGAGAGAGAGAGAG]AA & 11 & $433-2413$ \\
ISSR35 & [AGAGAGAGAGAGAGAG]TA & 11 & $329-3432$ \\
ISSR39 & [ACGACGACGACGACGACG] & 15 & $292-2975$ \\
ISSR40 & [ACCACCACCACCACCACC] & 13 & $488-2547$ \\
ISSR45 & [ACACACACACACACAC]GC & 10 & $466-2232$ \\
ISSR47 & [ACACACACACACACAC]GT & 13 & $222-1886$ \\
ISSR50 & [TGTGTGTGTGTGTGTG]AG & 13 & $238-3302$ \\
ISSR53 & [TGTGTGTGTGTGTGTG]GC & 11 & $458-2846$ \\
ISSR55 & [TGTGTGTGTGTGTGTG]GG & 5 & $409-2577$ \\
ISSR59 & [AGAGAGAGAGAGAGAG]GC & 11 & $239-2665$ \\
ISSR60 & [AGAGAGAGAGAGAGAG]GG & 13 & $349-2218$ \\
ISSR62 & [AGAGAGAGAGAGAGAG]CA & 13 & $218-2218$ \\
ISSR63 & [AGAGAGAGAGAGAGAG]CT & 11 & $285-3536$ \\
ISSR64 & [AGAGAGAGAGAGAGAG]CG & 11 & $386-2964$ \\
ISSR65 & [AGAGAGAGAGAGAGAG]CC & 8 & $307-4209$ \\
ISSR67 & [TCTCTCTCTCTCTCTC]CC & 15 & $369-2433$ \\
ISSR76 & [AGTCAGTCAGTCAGTC] & 8 &
\end{tabular}

Letters in brackets represent the repeat core sequence included in the ISSR primer.

ISSR fragments behaved as dominant markers, and they were scored for the presence (1) or absence (0) of homologous fragments for all accessions. Electrophoretograms were automatically scored with the JS-300 software (Genebase Co. Ltd., China); the faint residue fragments were discarded. Pairwise comparisons between isolates were made using the coef- 
ficient of Nei (1979): $\mathrm{S}_{\mathrm{ij}}=2 \mathrm{~N}_{\mathrm{ij}} /\left(\mathrm{N}_{\mathrm{i}}+\mathrm{N}_{\mathrm{j}}\right)$, where $N_{i}$ represents number of polymorphic bands of the $i^{\text {th }}$ accession, $N_{j}$ represents number of polymorphic bands of the $j^{\text {th }}$ accession, and $N_{i j}$ represents the number of shared polymorphic bands between $i^{\text {th }}$ and the $j^{\text {th }}$ accession.

\section{Data analysis}

DSI data were collected from two repeated inoculations conducted from April to June and August to November in 2004. The average DSI of isolates was compared using the Duncan multiple range test with analysis of variance in SAS (SAS Institute, 6.03 edn., Cary, NC, USA). Cluster analysis was conducted to visualize the groupings and their relations to pathogenicity based on genetic distance using PROC CLUSTER and further using PROC COORDINATE in SAS.

\section{RESULTS}

\section{Morphological characters of $\boldsymbol{V}$. dahliae isolates}

The morphological characters of the 12 isolates from eggplant cultivated in six geographic regions of northeast China are shown in Table 3. Morphological variations were obvious in mycelium color, aerial hypha, and sclerotium density, which were sufficient to present 3 morphotypes of hypha, hypha-sclerotia, and sclerotia. The 12 isolates had distinct sclerotium and conidium sizes. The length of sclerotia ranged from 26.3 to $62.0 \mu \mathrm{m}$ and width from 18.6 to $47.0 \mu \mathrm{m}$, and the length of conidia ranged from 4.7 to $8.0 \mu \mathrm{m}$ and width from 2.7 to $4.6 \mu \mathrm{m}$ (see Table 3).

Table 3. Morphological characters of 12 Chinese isolates of Verticillium dahliae from cultivated eggplant.

\begin{tabular}{|c|c|c|c|c|c|c|c|c|}
\hline \multirow[t]{3}{*}{ Isolate } & \multicolumn{4}{|c|}{ Morphological characters } & \multicolumn{4}{|c|}{ Size $(\mu \mathrm{m})$} \\
\hline & \multirow[t]{2}{*}{ Mycelium color } & \multirow[t]{2}{*}{ Aerial hypha } & \multirow[t]{2}{*}{ Sclerotium density } & \multirow[t]{2}{*}{ Morphotype } & \multicolumn{2}{|c|}{ Sclerotia } & \multicolumn{2}{|c|}{ Conidia } \\
\hline & & & & & Length & Width & Length & Width \\
\hline Vd196 & White & Medium & Sparse & Hy & 26.3 & 18.6 & 4.9 & 2.7 \\
\hline Vd198 & White & Abundant & Sparse & HS & 50.0 & 29.8 & 7.3 & 4.3 \\
\hline $\mathrm{Vd} 210$ & White & Medium & Sparse & HS & 51.8 & 46.0 & 5.4 & 2.8 \\
\hline $\mathrm{Vd} 200$ & Mixture & Abundant & Sparse & HS & 59.5 & 47.0 & 6.7 & 4.2 \\
\hline Vd201 & Mixture & Abundant & Medium & HS & 62.0 & 45.8 & 6.9 & 3.6 \\
\hline Vd202 & Black & Medium & Medium & HS & 39.3 & 31.8 & 5.8 & 3.2 \\
\hline Vd206 & Mixture & Seldom & Medium & $\mathrm{Sc}$ & 43.5 & 35.3 & 4.8 & 2.7 \\
\hline Vd207 & White & Medium & Medium & HS & 60.3 & 40.3 & 6.3 & 3.6 \\
\hline Vd197 & Mixture & Medium & Dense & HS & 45.1 & 32.1 & 5.9 & 4.3 \\
\hline Vd199 & White & Seldom & Dense & $\mathrm{Sc}$ & 49.3 & 43.0 & 4.8 & 4.6 \\
\hline Vd203 & Mixture & Seldom & Dense & $\mathrm{Sc}$ & 49.3 & 42.8 & 4.7 & 4.2 \\
\hline $\mathrm{Vd} 204$ & Black & Abundant & Dense & HS & 47.5 & 36.8 & 8.0 & 3.2 \\
\hline
\end{tabular}

The length and width measurements are the average of 20 sclerotia or conidia. Hy = hypha; HS = hypha-sclerotium; $\mathrm{Sc}=$ sclerotium.

\section{Pathogenicity of $V$. dahliae isolates}

Dipping of roots of 3 differential eggplant cultivars in a conidial suspension of 12 $V$. dahliae isolates induced distinct leaf symptoms and vascular discoloration. The DSI data 35 days after inoculation varied between isolates and ranged from 5.8 to 40.0 on the eggplant 
accession CGN18564, from 7.8 to 54.4 on the accession Sm97161, and from 23.8 to 81.6 on the accession Sm90017 (Table 4). Based on the individual reactions of 3 eggplant differential cultivars to V. dahliae inoculations, only 3 isolates - Vd196, Vd198, and Vd210 - were categorized into a defoliating pathotype with strong virulence (see Table 4). The remaining isolates were categorized into a non-defoliating pathotype with moderate virulence (isolates Vd197, Vd200, Vd202, Vd206, and Vd207) or weak virulence (isolates Vd199, Vd201, Vd203, and Vd204; see Table 4).

\begin{tabular}{|c|c|c|c|c|c|}
\hline \multirow[t]{2}{*}{ Isolate } & \multicolumn{3}{|c|}{ Mean DSI values and cultivar reaction } & \multirow[t]{2}{*}{ Pathotype } & \multirow[t]{2}{*}{ Virulence } \\
\hline & CGN18564 & Sm97161 & Sm90017 & & \\
\hline Vd196 & $40.0(\mathrm{MR})$ & $54.4(\mathrm{~S})$ & $81.6(\mathrm{~S})$ & Defoliating & Strong \\
\hline Vd198 & $29.2(\mathrm{MR})$ & $47.8(\mathrm{~S})$ & $62.1(\mathrm{~S})$ & Defoliating & Strong \\
\hline $\mathrm{Vd} 210$ & $35.2(\mathrm{MR})$ & 42.2 (MR) & $76.2(\mathrm{~S})$ & Defoliating & Strong \\
\hline Vd197 & $20.0(\mathrm{R})$ & 31.1 (MR) & $49.5(\mathrm{~S})$ & Non-defoliating & Moderate \\
\hline $\mathrm{Vd} 200$ & $22.5(\mathrm{R})$ & $32.2(\mathrm{MR})$ & $47.6(\mathrm{~S})$ & Non-defoliating & Moderate \\
\hline Vd202 & $20.0(\mathrm{R})$ & 30.0 (MR) & $47.7(\mathrm{~S})$ & Non-defoliating & Moderate \\
\hline Vd206 & $23.8(\mathrm{R})$ & 40.0 (MR) & $60.0(\mathrm{~S})$ & Non-defoliating & Moderate \\
\hline Vd207 & $23.8(\mathrm{R})$ & 37.8 (MR) & $52.4(\mathrm{~S})$ & Non-defoliating & Moderate \\
\hline Vd199 & $17.5(\mathrm{R})$ & 37.8 (MR) & 42.9 (MR) & Non-defoliating & Weak \\
\hline Vd201 & $10.0(\mathrm{R})$ & $14.4(\mathrm{R})$ & $48.6(\mathrm{~S})$ & Non-defoliating & Weak \\
\hline Vd203 & $14.2(\mathrm{R})$ & $13.3(\mathrm{R})$ & 37.1 (MR) & Non-defoliating & Weak \\
\hline $\mathrm{Vd} 204$ & $5.8(\mathrm{R})$ & $7.8(\mathrm{R})$ & $23.8(\mathrm{R})$ & Non-defoliating & Weak \\
\hline
\end{tabular}

The disease severity index (DSI) values are the average of eight plants in each eggplant accession. Reaction of eggplant differentials to $V$. dahliae inoculations: $\mathrm{R}=$ resistance; $\mathrm{MR}=$ moderate resistance; $\mathrm{S}=$ susceptible with their respective DSI values of $<25.0$, between 25.1 and 45.0, and $>45.1$. Pathotype and virulence of $V$. dahliae isolates based on reaction to three eggplant accessions or differentials; defoliating (strong virulence) or nondefoliating (moderate or weak virulence).

Pearson's correlation coefficients were calculated to explore the correlations among pathogenicity, morphological characters, and geographic origins (Table 5). Significant relationships were detected between morphotype and morphological traits, such as aerial hypha and sclerotium density but the association of morphotype with aerial hypha was negative. Nevertheless, pathotype was closely associated with sclerotium density and defoliating/nondefoliating type but unrelated to geographic origins.

\section{ISSR-PCR characterization of $V$. dahliae isolates}

The selected 28 ISSR primers amplified 1644 highly reproducible fragments ranging from 220 to $4200 \mathrm{bp}$ from the genomic DNA of $12 \mathrm{~V}$. dahliae isolates. Of all the reproducible fragments, $18.5 \%$ of ISSRs were polymorphic. The number of polymorphic fragments ranged from 5 (ISSR55) to 21 (ISSR25). The ISSR-PCR patterns of $V$. dahliae isolates using primer ISSR32 are shown in Figure 1. Interestingly, 10 primers rich in AG repeats - for instance, ISSR32 - amplified abundant fragments in eggplant isolates. The dendrogram derived from the cluster analysis of the ISSR-PCR fingerprints separated eggplant isolates into two groups, 'I and II', at the considerably low dissimilarity level of 0.15 (Figure 2). The Nei's distance, revealed by all electrophoresis patterns, was 0.19 between groups I and II. The genetic diversity index ranged from 0.26 to 0.69 . 
Table 5. Pearson's correlation coefficient among morphological characters, geographical origins, and pathotypes.

\begin{tabular}{|c|c|c|c|c|c|c|c|c|c|c|c|}
\hline \multirow[t]{2}{*}{ Character } & \multirow[t]{2}{*}{ Pathotype } & \multirow{2}{*}{$\begin{array}{l}\text { Mycelium } \\
\text { color }\end{array}$} & \multirow{2}{*}{$\begin{array}{l}\text { Aerial } \\
\text { hypha }\end{array}$} & \multirow{2}{*}{$\begin{array}{c}\text { Sclerotium } \\
\text { density }\end{array}$} & \multirow{2}{*}{ Morphotype } & \multicolumn{2}{|c|}{ Sclerotia } & \multicolumn{2}{|c|}{ Conidia } & \multirow[t]{2}{*}{ Origin } & \multirow{2}{*}{$\begin{array}{l}\mathrm{D} / \mathrm{ND} \\
\text { type }\end{array}$} \\
\hline & & & & & & Length & Width & Length & Width & & \\
\hline \multirow{2}{*}{ Pathotype } & 1.00 & 0.32 & -0.23 & 0.79 & 0.40 & 0.38 & 0.22 & 0.35 & 0.32 & 0.23 & 0.87 \\
\hline & - & $\underline{0.27}$ & $\underline{0.44}$ & $\leq 0.001^{*}$ & $\underline{0.16}$ & $\underline{0.18}$ & $\underline{0.45}$ & $\underline{0.22}$ & $\underline{0.27}$ & $\underline{0.42}$ & $\leq 0.001^{*}$ \\
\hline \multirow[t]{2}{*}{ Mycelium color } & & $\overline{1.00}$ & $\overline{0.10}$ & $\overline{0.32}$ & $-\overline{-0.03}$ & -0.05 & -0.11 & -0.15 & $-\overline{-0.04}$ & -0.19 & 0.42 \\
\hline & & - & $\underline{0.72}$ & 0.27 & $\underline{0.93}$ & $\underline{0.86}$ & $\underline{0.71}$ & $\underline{0.60}$ & $\underline{0.89}$ & $\underline{0.51}$ & $\underline{0.14}$ \\
\hline \multirow[t]{2}{*}{ Aerial hypha } & & & $\overline{1.00}$ & $\overline{-0.59}$ & $-\overline{-0.69}$ & $\overline{-0.03}$ & $\overline{0.37}$ & $-\overline{-0.07}$ & $\overline{0.18}$ & $\overline{0.02}$ & $-\overline{-0.06}$ \\
\hline & & & - & $\underline{0.03} *$ & $\underline{0.01} *$ & $\underline{0.92}$ & $\underline{0.19}$ & $\underline{0.80}$ & $\underline{0.53}$ & $\underline{0.95}$ & $\underline{0.83}$ \\
\hline \multirow[t]{2}{*}{ Sclerotium density } & & & & $\overline{1.00}$ & $\overline{0.55}$ & $\overline{0.08}$ & $-\overline{0.11}$ & $\overline{0.24}$ & $\overline{0.23}$ & $\overline{0.04}$ & $\overline{0.68}$ \\
\hline & & & & 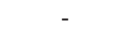 & $\underline{0.04 *}$ & $\underline{0.79}$ & $\underline{0.70}$ & $\underline{0.40}$ & $\underline{0.42}$ & $\underline{0.88}$ & $\underline{0.01 *}$ \\
\hline \multirow[t]{2}{*}{ Morphotype } & & & & & $\overline{1.00}$ & $\overline{0.50}$ & $\overline{0.22}$ & $\overline{0.25}$ & $\overline{0.18}$ & $\overline{0.10}$ & $\overline{0.24}$ \\
\hline & & & & & - & $\underline{0.07}$ & $\underline{0.46}$ & $\underline{0.38}$ & $\underline{0.54}$ & $\underline{0.74}$ & $\underline{0.40}$ \\
\hline \multirow[t]{2}{*}{ Sclerotium length } & & & & & & $\overline{1.00}$ & $\overline{0.82}$ & $\overline{0.26}$ & $\overline{0.14}$ & $\overline{0.41}$ & $\overline{0.37}$ \\
\hline & & & & & & - & $\leq 0.001 *$ & $\underline{0.38}$ & $\underline{0.63}$ & $\underline{0.15}$ & $\underline{0.20}$ \\
\hline \multirow[t]{2}{*}{ Sclerotium width } & & & & & & & $\overline{1.00}$ & 0.23 & 0.31 & 0.33 & $\overline{0.31}$ \\
\hline & & & & & & & - & $\underline{0.42}$ & 0.28 & $\underline{0.25}$ & $\underline{0.27}$ \\
\hline \multirow{2}{*}{ Conidium length } & & & & & & & & 1.00 & $\overline{0.51}$ & $\overline{-0.30}$ & $\overline{0.27}$ \\
\hline & & & & & & & & - & $\underline{0.06}$ & $\underline{0.30}$ & $\underline{0.35}$ \\
\hline \multirow[t]{2}{*}{ Conidium width } & & & & & & & & & $\overline{1.00}$ & $-\overline{-0.35}$ & $\overline{0.40}$ \\
\hline & & & & & & & & & - & 0.22 & $\underline{0.16}$ \\
\hline \multirow[t]{2}{*}{ Origin } & & & & & & & & & & $\overline{1.00}$ & $\overline{0.19}$ \\
\hline & & & & & & & & & & - & $\underline{0.52}$ \\
\hline D/ND type & & & & & & & & & & & $\overline{1.00}$ \\
\hline
\end{tabular}

The underlined values are the $\mathrm{P}$ values of the $t$-test with hypothesis of $\mathrm{H}_{0}: \mathrm{r}_{\mathrm{h} 0}=0 . \mathrm{D} / \mathrm{ND}$ type represents defoliating and non-defoliating types, respectively. *Represents significance to $\mathrm{H}_{0}: \mathrm{r}_{\mathrm{h} 0}=0(\mathrm{P}>|\mathrm{r}|)$ at the level of $\alpha=0.05$.

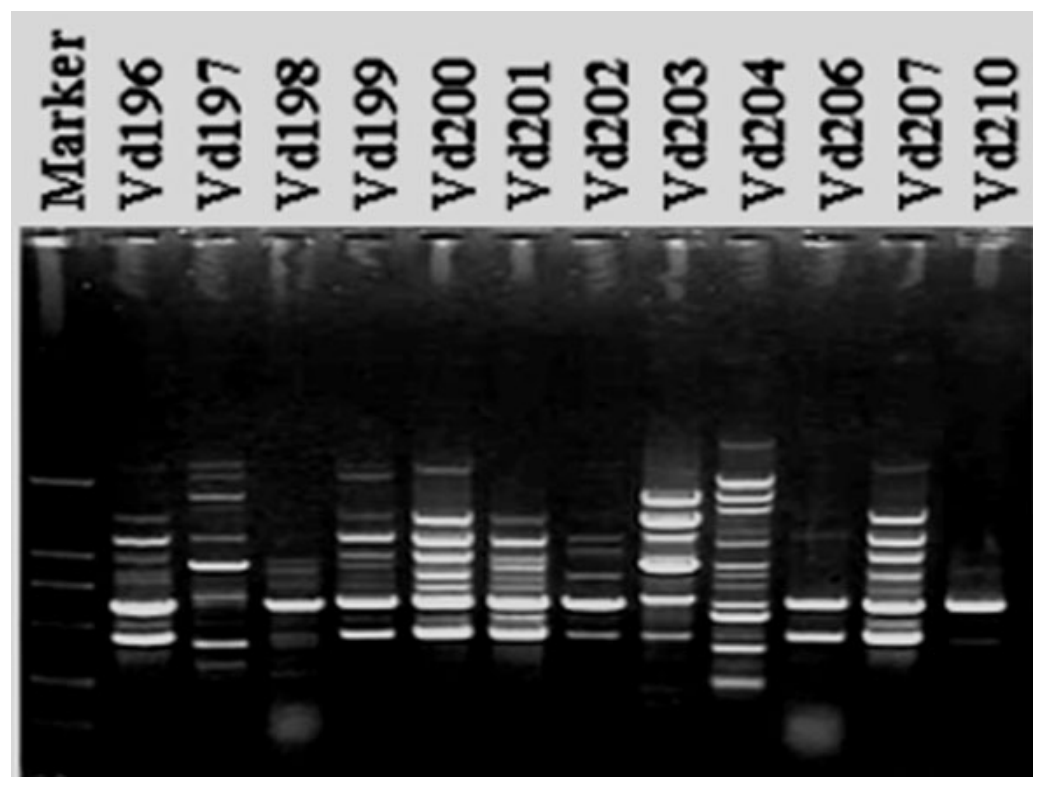

Figure 1. ISSR-PCR genomic profiles of Verticillium dahliae isolates generated with primer ISSR32. Fragments were separated electrophoretically on agarose gel followed by ethidium bromide staining. Lane Marker = molecular weight marker DL2000 (Takara Co. Ltd., Japan). 


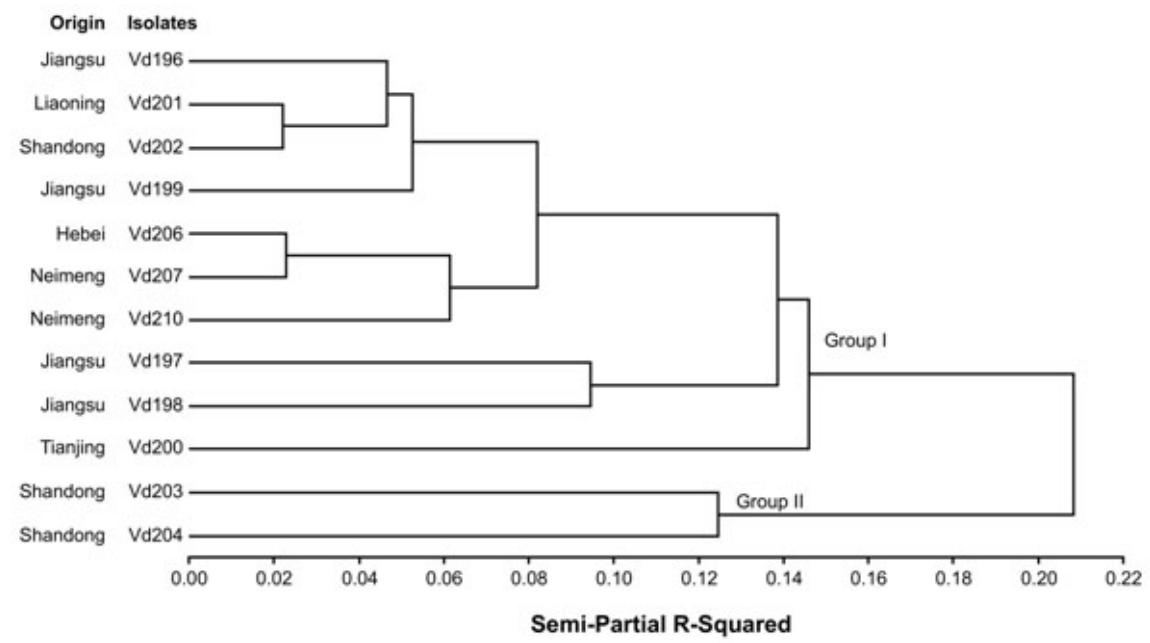

Figure 2. Dendrogram of 12 Verticillium dahliae isolates based on ISSR fingerprinting data (Ward method). Two groups of eggplant isolates, at the level of semi-partial R-squared of 0.15 , were indicated by group I and group II.

Principal coordinate analysis was conducted to gain further insight into the relatedness between ISSR-PCR patterns and pathogenicity as well as interactions among hosts, isolates, and pathogenicity. This analysis can extract individual eigenvectors from a similarity matrix, which accounts for a proportion of the total variance in the data (Figure 3). Figure 3 depicts the distinct separation of groups and substantiates the results in a cluster analysis. Prin 1 and Prin 2 corresponding to two axes were sufficient to explain 18.90 and $16.13 \%$ of total variation, respectively. The main original variables that separated group I from group II along Prin1 were found mostly in accordance with ISSR09; the counterpart along Prin2 included ISSR67.

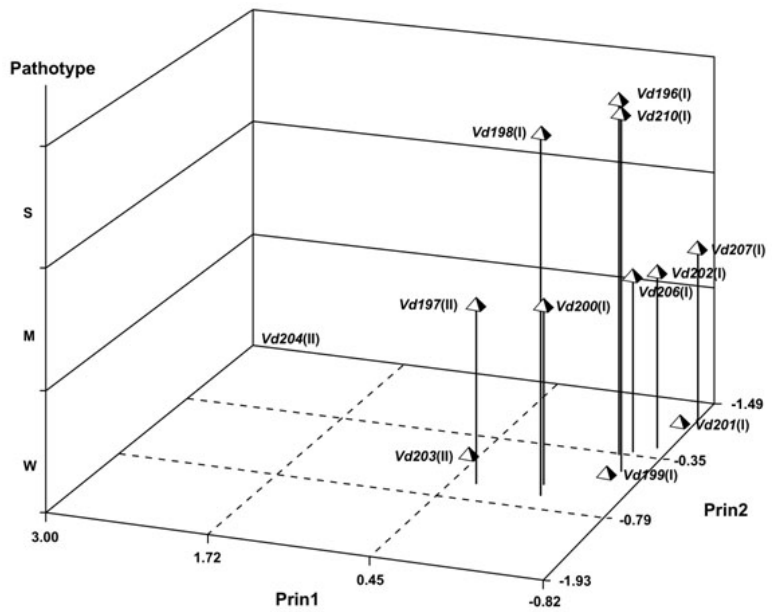

Figure 3. Associations among 12 Verticillium dahliae isolates revealed by principal coordinate analysis using 341 ISSR locus data. 


\section{DISCUSSION}

The characterization of morphological, virulence, and genetic variations among $V$. dahliae isolates from different geographic origins can be critical for establishing effective diseasemanagement strategies including breeding programs aimed at producing plant cultivars resistant to Verticillium wilt disease. This study was conducted to elucidate any differences within limited eggplant isolates of $V$. dahliae obtained from six provinces of China based on pathogenicity tests on 3 eggplant accessions, morphological observations on growth medium, and ISSR-PCR fingerprinting of genomic DNA. The V. dahliae isolates from Chinese cultivated eggplant varied both in virulence reactions in 3 eggplant accessions and in morphology. ISSR markers separated these isolates into two groups at a very low dissimilarity level.

The eggplant isolates were divided into strong, moderate and weak virulence types based on their overall DSI score in the resistant, moderately resistant, and susceptible eggplant accessions. The isolates were also categorized as defoliating and non-defoliating pathotypes. Based on a moderately resistant response on the resistant (CGN18564) or moderately resistant to susceptible response on the moderately resistant (Sm97161) or susceptible response on the susceptible (Sm90017) eggplant accession, 3 isolates were categorized as a defoliating pathotype with strong virulence. The remaining isolates were categorized as a non-defoliating pathotype with moderate to weak virulence. Both defoliating and non-defoliating pathotypes have also been described for $V$. dahliae isolates from cotton, in which each type differed considerably in virulence (Schnathorst and Mathre, 1966; Bell, 1994; Bejarano-Alcázar et al., 1996). All 3 defoliating type isolates displayed the strongest pathogenicity compared to that of the other isolates and were clustered into group I based on cluster analysis of ISSR-PCR fingerprinting of genomic DNA. However, no individual ISSR marker could distinguish the two pathotypes. Pérez-Artés et al. (2000) have reported success in the molecular characterization of defoliating and non-defoliating $V$. dahliae isolates from cotton in Spain. The differences in their results and those of the present study might relate to the clear-cut differences between the two pathotypes (Schnathorst and Mathre, 1966; Presley, 1969; Bell, 1994; Bejarano-Alcázar et al., 1996). More diverse isolates and their pathogenicity may be involved, and these need further investigation.

The eggplant $V$. dahliae isolates had distinct sizes of sclerotia and conidia and morphological variations were present in mycelium color, aerial hypha, and sclerotium density. Three morphotypes of hypha, hypha-sclerotia, and sclerotia were described based on these variations. No significant relationship was found between morphological characters and molecular groups among $V$. dahliae isolates. Similarly, morphotypes were indistinguishable within each ISSR group. Group I isolates were represented by all 3 morphotypes, whereas both isolates in group II had a different morphotype. Pathotypes were morphologically associated with sclerotium density and defoliating/non-defoliating type but unrelated to geographic origins. The results of this study provide no evidence to support a clear relationship between pathogenicity and a number of traits, e.g., germination rate, spore size, and sporulation ability of some Verticillium spp, as suggested by Hall (1984) and Masuda and Kikuchi (1992).

ISSR-PCR of genomic DNA distinctly separated $V$. dahliae isolates into two groups but the produced banding patterns were unrelated to morphotypes and defoliating or non-defoliating pathotypes. However, the banding patterns correlated with geographic origin. In general, isolates of the same or neighboring geographic origins tended to cluster together. Group I comprised 10 isolates from a geographically continuous area. Four isolates from Jiangsu 
were within main cluster, i.e., group I. Group II comprised two isolates from Shandong. This clustering might be due to the sharing of similar climate and cropping habits by neighboring provinces. Even seed for growing eggplants in these provinces might frequently be provided by the same seed company. Therefore, detecting similar or even the same isolates from two such locations through infected seeds may not be surprising (Kadow, 1934). However, this phenomenon needs further investigation. The divisions of $V$. dahliae isolates in two groups have also been suggested by Okoli et al. (1993) on the basis of RFLP patterns.

Similar to morphotypes and ISSR-PCR-based grouping, pathotypes were also indistinguishable based on ISSR-PCR fingerprinting. Each group consisted of two or more pathotypes, which demonstrated no relationships between pathotype and ISSR-based grouping. Ramsay et al. (1996) have found no correlation between banding patterns and virulence characters based on RAPD analysis of cotton isolates of $V$. dahliae in Australia. Similarly, Bhat and Subbarao (1999) have observed no correlation in pathogenicity, VCGs, and RAPD banding patterns among $V$. dahliae isolates from various hosts, including eggplant. Isolates of $V$. dahliae within each VCGs can vary considerably with respect to virulence on their respective hosts (Gennari et al., 2000).

Highly significant host plant-isolate interactions in our study implied that eggplant isolates, which had very narrow genetic variation, exhibited significant variation of pathogenicity, suggesting that host specificity was not only working among plant species but also among cultivars within unique plant species. The genetic diversity index ranged from 0.26 to 0.69 and was even less than that in cotton and potato isolates that have limited diversity within populations of $V$. dahliae (Joaquim and Rowe, 1991; Elena and Paplomatas, 1998; Hiemstra and Rataj-Guranowska, 2000). Genetic variation among eggplant $V$. dahliae isolates was very narrow compared to that of isolates from other hosts. However, this genetic variation needs to be demonstrated with large numbers of isolates.

The pathogenicity tests and morphological observations carried on a limited number of eggplant $V$. dahliae isolates revealed that differences in pathogenicity and morphology do exist among $V$. dahliae isolates from Chinese cultivated eggplant. Three pathotypes and morphotypes were documented. Further, pathotypes were morphologically associated to sclerotium density but not to geographical origin. ISSR-PCR of genomic DNA distinctly separated $V$. dahliae isolates into two groups but the produced banding patterns were unrelated to pathotypes, virulence, or morphotypes. However, they were related to geographic origin. The significant host plant-isolate interactions were detected indicating that host specificity was not only working among plant species but also among cultivars within unique plant species.

\section{ACKNOWLEDGMENTS}

We are indebted to Ms. Lin Lin, Institute of Plant Protection/Jiangsu Academy of Agricultural Sciences, Nanjing, for providing several Verticillium dahliae isolates.

\section{REFERENCES}

Arora DK, Hirsch PR and Kerry BR (1996). PCR-based molecular discrimination of Verticillium chlamydosporium isolates. Mycol. Res. 100: 801-809.

Bejarano-Alcázar J, Blanco-López MA, Melero-Vara JM and Jiménez-Díaz RM (1996). Etiology, importance, and distribution of Verticillium wilt of cotton in southern Spain. Plant Dis. 80: 1233-1238. 
Bell AA (1994). Mechanisms of Disease Resistance in Gossypium Species and Variation in Verticillium dahliae. In: Challenging the Future: Proceedings of World Cotton Research Conference 1 (Constable GA and Forrester NW, eds.). CSIRO, Melbourne, 225-235.

Bhat RG and Subbarao KV (1999). Host Range Specificity in Verticillium dahliae. Phytopathology 89: 1218-1225.

Carder JH and Barbara DJ (1991). Molecular variation and restriction fragment length polymorphisms (RFLPs) within and between six species of Verticillium. Mycol. Res. 95: 935-942.

Carder JH and Barbara DJ (1994). Molecular variation within some Japanese isolates of Verticillium dahliae. Plant Pathol. 43: 947-950.

Dobinson KF, Patterson NA, White GJ and Grant S (1998). DNA fingerprinting and vegetative compatibility analysis indicate multiple origins for Verticillium dahliae race 2 tomato isolates from Ontario, Canada. Mycol. Res. 102: 1089-1095.

Elena K and Paplomatas EJ (1998). Vegetative compatibility groups within Verticillium dahliae isolates from different hosts in Greece. Plant Pathol. 47: 635-640.

Fradin EF and Thomma BP (2006). Physiology and molecular aspects of Verticillium wilt diseases caused by $V$. dahliae and V. albo-atrum. Mol. Plant Pathol. 7: 71-86.

Gennari SD, Ercole N and Mirotti A (2000). Vegetative Compatibility Groupings Among Verticillium dahliae Kleb. Isolates from Vegetable Crops. In: Advances in Verticillium: Research and Disease Management (Tjamos EC, Rowe RC, Heale JB and Fravel DR, eds.). APS Press, St. Paul, 112-116.

Grünig CR, Sieber TN and Holdenrieder O (2001). Characterisation of dark septate endophytic fungi (DSE) using intersimple-sequence-repeat-anchored polymerase chain reaction (ISSR-PCR) amplification. Mycol. Res. 105: 24-32.

Hagiwara H (1990). Differentiation of the pathogenicity of Verticillium dahliae in Japan. Plant Prot. 44: 299-303.

Hall RA (1984). Epizootic potential for aphids of different isolates of the fungus Verticillium lecanii. Entomophaga 29: 311-321.

Hiemstra JA and Rataj-Guranowska M (2000). Vegetative Compatibility Groups in Verticillium dahliae in the Netherlands. In: Advances in Verticillium: Research and Disease Management. (Tjamos EC, Rowe RC, Heale JB and Fravel DR, eds.). APS Press, St. Paul, 100-102.

Joaquim TR and Rowe RC (1990). Reassessment of vegetative compatibility relationships among strains of Verticillium dahliae using nitrate-nonutilizing mutants. Phytopathology 80: 1160-1166.

Joaquim TR and Rowe RC (1991). Vegetative compatibility and virulence of strains of Verticillium dahliae from soil and potato plants. Phytopathology 81: 552-558.

Kadow KJ (1934). Seed transmission of Verticillium wilt of eggplants and tomatoes. Phytopathology 24: 1265-1268.

Klosterman SJ, Atallah ZK, Vallad GE and Subbarao KV (2009). Diversity, pathogenicity, and management of Verticillium species. Annu. Rev. Phytopathol. 47: 39-62.

Koike M, Fujita M, Nagao H and Ohshima S (1996). Random amplified polymorphic DNA analysis of Japanese isolates of Verticillium dahliae and V. albo-atrum. Plant Dis. 80: 1224-1227.

Komatsu T, Sumino A and Kageyama K (2001). Characterization of Verticillium dahliae isolates from potato on Hokkaido by random amplified polymorphic DNA (RAPD) and REP-PCR analyses. J. Gen. Plant Pathol. 67: 23-27.

Lee SB and Taylor JW (1990). Isolation of DNA from Fungal Mycelia and Single Spores. In: PCR Protocols: A Guide to Methods and Applications (Innis MA, Gelfand DH, Sninsky JJ and White TJ, eds.). Academic Press, San Diego, 282-287.

Masuda T and Kikuchi O (1992). Pathogenicity of Verticillium lecanii isolates to whitefly and aphids. Jap. J. Appl. Entomol. Zool. 36: 239-245.

Nei M (1979). Proportion of informative families for genetic counseling with linked marker genes. Jinrui. Idengaku. Zasshi 24: 131-142.

Okoli CAN, Carder JH and Barbara DJ (1993). Molecular variation and sub-specific groupings within Verticillium dahliae. Mycol. Res. 97: 233-239.

Okoli CAN, Carder JH and Barbara DJ (1994). Restriction fragment length polymorphisms (RFLPs) and the relationships of some host-adapted isolates of Verticillium dahliae. Plant Pathol. 43: 33-40.

Pérez-Artés E, García-Pedrajas MD, Bejarano-Alcázar J and Jiménez-Díaz RM (2000). Differentiation of cottondefoliating and nondefoliating pathotypes of Verticillium dahliae by RAPD and specific PCR analyses. Eur. J. Plant Pathol. 106: 507-517.

Presley JT (1969). Growth response of Verticillium albo-atrum to sanguinarine in nutrient agar. Phytopathology 59: 1968-1969.

Puhalla JE and Hummel M (1983). Vegetative compatibility groups within Verticillium dahliae. Phytopathology 73: 1305-1308.

Ramsay JR, Multani DS and Lyon BR (1996). RAPD-PCR identification of Verticillium dahliae isolates with differential pathogenicity on cotton. Aust. J. Agri. Res. 47: 681-693.

Rodrigues KF, Sieber TN, Grunig CR and Holdenrieder O (2004). Characterization of Guignardia mangiferae isolated from tropical plants based on morphology, ISSR-PCR amplifications and ITS1-5.8S-ITS2 sequences. Mycol. Res. 
108: 45-52.

Schnathorst WC and Mathre DE (1966). Host range and differentiation of a severe form of Verticillium albo-atrum in cotton. Phytopathology 56: 1155-1161.

Usami T, Abiko M, Shishido M and Amemiya Y (2002). Specific detection of tomato pathotype of Verticillium dahliae by PCR assays. J. Gen. Plant Pathol. 68: 134-140.

Wang S, Miao X, Zhao W, Huang B, et al. (2005). Genetic diversity and population structure among strains of the entomopathogenic fungus, Beauveria bassiana, as revealed by inter-simple sequence repeats (ISSR). Mycol. Res. 109: 1364-1372.

Wilhelm S (1955). Longevity of the Verticillium wilt fungus in the laboratory and field. Phytopathology 45: 180-181.

Xiao YH and Lin BQ (1995). Identification of Verticillium wilt resistance on eggplant germplasm. Chin. Veg. 1: 32-33.

Yi J (1998). Advances of breeding on eggplant for Verticillium wilt resistance. Chin. Veg. 6: 52-55.

Yi J, Chen J and Gao J (2000). Evaluation of Verticillium wilt resistance on eggplant germplasm (Chinese). Jiangsu Agri. Sci. 6: 54-57.

Zietkiewicz E, Rafalski A and Labuda D (1994). Genome fingerprinting by simple sequence repeat (SSR)-anchored polymerase chain reaction amplification. Genomics 20: 176-183. 